\title{
A compreensão dos saberes ecoculturais no ponto focal urbano das queimas no Tocantins
}

As queimadas são ações planejadas de origem antrópica e quando estes fenômenos de queima saem do controle humano se iniciam os incêndios florestais, os quais resultam em impactos multidisciplinares. No Tocantins, as queimas, queimadas e incêndios florestais são práticas dos diferentes sujeitos ecoculturais motivados pelo contexto econômico e pela expansão de novas área limítrofes. O ponto focal urbano das queimas no Tocantins é o Bairro Lagoa da Ilha, localizado no município de Lagoa da Confusão, e esta pesquisa objetiva compreender os saberes ecoculturais dos sujeitos residentes neste lócus. A metodologia é de caráter quali-quantitativo de tipologia explicativa segundo os objetivos, com uso da pesquisa bibliográfica e análise documental como fontes de informação, seguida de uma pesquisa de campo real com aplicação dos instrumentos de questionário e entrevista, com possibilidade de participação em um Curso de Formação de Brigadista Florestal, além da presença da Teoria Fundamentada e da Pesquisa-Ação. Os resultados e a discussão apontam a compreensão dos saberes ecoculturais ao mesmo tempo em que apontam para a necessidade de uma comparação analítica das variáveis de focos de calor e área queimada, ao que se delimitou a contraposição entre os incêndios florestais Classe I e Classe V. Ao final deste estudo se conclui que o resultado foi de caráter total, uma vez que o objetivo delimitado foi alcançado em sua plenitude.

Palavras-chave: Saberes ecoculturais; Incêndios florestais; Bairro Lagoa da llha.

\section{The ecocultural knowledge comprehension at urban hotspot points in Tocantins}

The fires are planned actions of anthropic origin and hen these burning phenomena out of human control start wildfires, which results in multidisciplinar impacts. At Tocantins, the burns, fires and wildfires are practices os different ecocultural subjects, motivatedny the economic contexto and the expansion of bordering áreas. The urban hotspot points in Tocantins is the Lagoa da Ilha District, located in Lagoa da Confusão County, and this research aims to comprehend the ecocultural knowledge of the resident subjects in this locus. The metodology is the quali-quantitative of exploratory typology according the objectives, with the use of bibliographic search and documental analysis like information sources, followed by real field research with application of the instruments questionnaire and interview, enabling participation in a Forest Brigade Professional Course, beyond the presence of Grounded Theory and of Research-Action. The results and the discussion points to comprehension of ecocultural knowledge in the meantime point to need an analytical comparison of the variables of hotspots and burnt área, to what was delimited the contraposition between wildfires Level I and Level V. At end of this study concludes that the result was total character, cause the delimited objetcive was reached in its fullness.

Keywords: Ecocultural knowledge; Wildfires; Lagoa da Ilha District.

Topic: Desenvolvimento, Sustentabilidade e Meio Ambiente

Reviewed anonymously in the process of blind peer.
Received: 01/04/2021

Approved: 28/04/2021
Cléber José Borges Sobrinho

Universidade Federal do Tocantins, Brasil http://lattes.cnpq.br/2925929082473530 http://orcid.org/0000-0001-7356-9116

cleberborgess@yahoo.com.br

Dernival Venâncio Ramos Júnior (iD

Universidade Federal do Tocantins, Brasil

http://lattes.cnpq.br/9941464654933458

http://orcid.org/0000-0001-5092-1199

dernivaljunior@gmail.com
Referencing this:

BORGES SOBRINHO, C. J.; RAMOS JÚNIOR, D. V.. A compreensão dos saberes ecoculturais no ponto focal urbano das queimas no Tocantins. Revista Ibero Americana de Ciências Ambientais, v.12, n.4, p.561575, 2021. DOI: http://doi.org/10.6008/CBPC21796858.2021.004.0043 


\section{INTRODUÇÃO}

As queimadas são ações antrópicas intencionais com planejamento para queimas em ambientes de vegetação, que resultam em danos desproporcionais e impactos nos meios social, ambiental e econômico; quando estes fenômenos fogem do controle humano originam os incêndios, e estima-se que suas conflagrações são responsáveis por cerca de 90\% dos incêndios florestais (CBMGO, 2017; SANTOS et al., 2018).

Os incêndios florestais atingem as áreas florestais, comunitárias e agropastoris, e como consequência, afetam as relações sociais de geração de renda, segurança alimentar, fornecimento de insumos e equipamentos, prestações de serviços de plantio e transporte, e, prejuízos aos consumidores finais das produções (MORELLO et al., 2017; CLEMENTE et al., 2017).

No Brasil, estas práticas de queima são fruto da colonização europeia, cujo foco principal à época era abertura de novas fronteiras para exploração vegetal e mineral, e este caráter geracional das práticas antrópicas intencionais é mais observado nos continentes América e África (AYANZ et al., 2018).

Pode-se citar como exemplo a queima de pastagens e de áreas florestais para plantio sob a justificativa de distribuição de renda por meio de empregos formais e produção de alimentos, todavia, temse por hábito realizar as queimas sem uma análise dos impactos primários e secundários à biodiversidade local (BORGES SOBRINHO et al., 2020a; 2020c).

Estas ações de queima caracterizam tanto espaços urbanos como rurais, além de delimitarem áreas ao potencial agropecuário, que quando somados aos fatores de rapidez e de baixo custo, tornam a prática de queima como a metodologia mais comum para tais processos (OLIVEIRA, 2018; BORGES SOBRINHO et al., 2020a).

O Tocantins possui características climatológicas e geomorfológicas favoráveis ao PIB Agropecuário e às incidências de queimadas e incêndios florestais, uma vez que os fatores clima, ambiente propício e ação humana contribuem para que este estado brasileiro seja o quarto colocado no ranking brasileiro ao longo da série histórica 2009-2018 (MARIANI et al., 2016; OLIVEIRA, 2018; TOCANTINS, 2019).

Considera-se ainda a variável extensão territorial, na qual o Tocantins ocupa a décima posição nacional, logo, a justificativa para os elevados índices de focos de calor ativo vincula a área de $277.621 \mathrm{Km}^{2}$ com as práticas antrópicas para incidências de queimas, queimadas e incêndios florestais (IBGE, 2019; BORGES SOBRINHO et al., 2020a).

Nesta perspectiva, este estudo objetiva compreender os saberes ecoculturais dos sujeitos do ponto focal urbano das queimas no Tocantins, por meio da seguinte abordagem tríplice: correlacionar os saberes ecoculturais com os fenômenos de queimas, aplicar uma entrevista aos sujeitos ecoculturais do ponto focal urbano tocantinense diante do queimar, e, promover um Curso de Formação de Brigadistas Florestais aos sujeitos voluntários desta pesquisa. 


\section{REVISÃO TEÓRICA}

\section{Os saberes ecoculturais e os fenômenos de queimas}

A terminologia ecocultural faz referência às práticas e ações culturais de um povo ou grupo que seguem tradições intergeracionais por meio de saberes históricos. Estes fundamentos fazem referência às abordagens multidisciplinares e permitem confrontos dialógicos para produção de conhecimentos integradores, ou seja, sem amarras para inserção de novos saberes (BICHARA, 2018; SOUZA, 2018).

Nesta concepção, os saberes ecoculturais relacionam diferentes sujeitos em uma perspectiva de relações interculturais e etnicidade dentro de um contexto subjetivo e territorial, o qual contribui no desenvolvimento de saberes próprios e na formação da identidade deste sujeito ecocultural (SOTOMAYOR et al., 2020).

A prática ecocultural deste sujeito pode ser observada entre as populações das áreas indígenas, comunidades quilombolas e agropastoris, que valorizam as lendas e as histórias passadas às crianças a cada geração, que ao crescer desenvolvem o sentimento de orgulho e realizam as mesmas práticas de seus antecedentes; este processo de aprendizagem não acontece em um ambiente formal e as salas de aulas podem variar entre riachos, árvores, campos e quintais (COELHO, 2003; ESCOBAR, 2005).

Estas práticas ecoculturais relacionam diferentes vivências de diversidade, estrutura e saberes adaptados às realidades específicas, e quando estas mesmas práticas estão presentes nas culturas tradicionais se observa a existência de um legado que valoriza as sustentabilidades socioecológicas e se veem inseridas nos contextos econômicos (SAL et al., 2018).

A presença de contextos econômicos e/ou políticos podem desencadear mudanças nas relações ecoculturais em virtude das necessidades orçamentário-familiares, que passam a ser a prioridade dos responsáveis pelo suprimento financeiro de sua família; ou seja, ainda que os sujeitos possuam a valorização histórico-cultural e o sentimento de preservação ambiental e social, muitos mantenedores familiares podem ter suas ações norteadas pela necessidade financeira de sustento (HAYMAEL, 2018).

A exemplo das queimas realizadas por sujeitos ecoculturais, destaca-se que a prática ecocultural da queima é decorrente dos processos históricos de colonização europeia para abertura de novas áreas limítrofes, também passou a ser empregada para a incineração das palhas e resíduos vegetais nos períodos pós-colheita, o que promoveu uma nova identidade ecocultural destes sujeitos (SOTOMAYOR et al., 2018; AYANZ et al., 2018).

Portanto, a identidade ecocultural de um sujeito referência o relacionamento de seus diferentes saberes com suas convivências, seja dentro ou fora de seu território, e sua discussão envolve as subjetividades ecológicas e as identidades ambientais de uma prática intencional, ainda que inconsciente.

Como resultado da formação da identidade ecocultural, tem-se o sujeito ecocultural, o qual se manifesta de forma individual fora de seu espaço territorial e de forma coletiva quando dentro de seu território. Este comportamento é observado no campesinato imigrante, que tem por hábito sair da zona rural e residir na zona urbana na condição de posseiro (TAVARES et al., 2020). 
Esta transição de saída do espaço rural e instalação no espaço urbano ocorre por vezes em virtude da expansão da fronteira agrícola, que passa ocupar novas zonas limítrofes e "empurra" os sujeitos ecoculturais para novas localidades, e estes passam a reproduzir seu modo de vida geracional e a recontextualizar seus saberes ecoculturais (ESCOBAR, 2005; HUONG et al., 2018).

Esta mudança domiciliar estabelece novas relações sociais cotidianas e abrange os elementos político, econômico, cultural e ambiental, os quais constituem novas práticas formadoras no viés econômico e profissional, ao mesmo tempo em que as transformações do novo espaço geográfico aglutinam os saberes camponeses com a dissemelhante rotina urbana (HANKINS, 2018).

Logo, um sujeito ecocultural que pratica o queimar em seu ambiente ecológico e social não pode ser alcançado somente por uma pesquisa observacional, pois desde a antiguidade o fogo é uma ferramenta de complexidades, usado para gerenciar ecossistemas, criar paisagens, realizar aberturas e acessos, garantir sobrevivência junto a plantas e animais, e, cultuar os mitos comunitários (LEPOFSKY et al., 2018).

Estes mitos comunitários são fenômenos complexos que se relacionam com seres complexos, cultuados em reuniões noturnas, geralmente ao redor de uma fogueira, e esta prática é comum em diferentes culturas, por se tratar de uma ação humana de caráter tácito (LYONS et al., 2018).

Em concordância a tais complexidades, White et al. (2011) aponta os relacionamentos entre o fogo e os seres humanos, uma vez que o fogo instiga nos seres humanos valores políticos à proteção e ao mesmo tempo os faz rever as condições históricas de sua importância à sobrevivência; enquanto Turner et al. (2003) apontam que o fogo é um elo inextricável entre os seres humanos e seus limites ecoculturais, pois representa em ambos a resiliência, a diversidade biológica, os saberes culturais e sobrevivência. Essa dicotomia representativa a qual abrange o relacionamento homem-fogo é uma perspectiva bachelardiana, a qual se configura na seguinte compreensão:

Dentre todos os fenômenos, é realmente o único capaz de receber tão nitidamente as duas valorizações contrárias: o bem e o mal. Ele brilha no Paraíso, abrasa no inferno. É doçura e tortura. Cozinha e apocalipse.

[...] O fogo é bem-estar e respeito. É um deus tutelar, bom e mau. Pode contradizer-se, por isso é um dos princípios de explicação universal. (BACHELARD, 1994)

O fogo se trata de um ente da natureza que abrange um comportamento de extremos, pois suas características perpassam tanto o bem como o mal de forma simultânea, e a humanidade, por meio de seus sujeitos ecoculturais, devem compreender sua essência e respeitar sua dicotomia (BACHELARD, 1994).

Portanto, na tentativa de compreender os sujeitos ecoculturais e suas práticas com o fogo, deve-se considerar não somente os dados quantitativos sobre a incidência dos focos de calor, mas também as crenças, a história cultural, os saberes, as tradições destes sujeitos e o meio ambiente no qual a residem, uma vez que a prática do queimar vincula saberes ecoculturais em uma dimensão interdisciplinar.

Diante do exposto, correlacionou-se os saberes ecoculturais com os fenômenos de queimas, não obstante, existe a necessidade de uma pesquisa de campo in loco no ponto focal urbano dos focos de calor ativo do Tocantins a fim de compreender as variáveis humanas e ambientais do ponto focal urbano das queimas no Tocantins. 


\section{A entrevista aos sujeitos ecoculturais e suas compreensões de queima}

No Tocantins, as queimadas apresentam caráter sazonal, com período de estiagem entre os meses de junho a novembro, quando ao final da tarde os produtores agrícolas aproveitam a menor temperatura do dia para realizarem as queimadas; e um período chuvoso de dezembro a maio, com incentivos à pecuária (BORGES et al., 2016; GIOVANELLI et al., 2016).

Tal prática de queima correlaciona o histórico das queimadas à expansão agrícola brasileira desde a década de 1980, pois a chamada "economia política" é tratada como interesse superior aos interesses ecoculturais e socioambientais, a título de uma "avareza pálida demais para se descrever" (DEAN, 1984; DEAN, 1996).

As queimas, queimadas e incêndios florestais na produção agropecuária são metodologias de impulso para a expansão agrícola, e na rotação de culturas e na limpeza de pastagens correspondem a um método ágil e barato, pois "as árvores derrubadas e queimadas produzem cinzas ricas em nutrientes que fertilizam o solo" que são levadas aos extratos de solo por meio das chuvas e processos de irrigação (SODRÉ, 2019).

Estas práticas de queima são de caráter histórico nas regiões agrícolas e praticada pelos sujeitos ecoculturais por motivações financeiras, o que aponta para uma correlação entre a produção agrícola e a prática do fogo (BORGES et al., 2016; RAYOL et al., 2020; BORGES SOBRINHO et al., 2020a).

A partir do conhecimento de que o ponto focal urbano dos focos de calor do Tocantins é o Bairro Lagoa da Ilha, do município de Lagoa da Confusão, houve aplicação de um Questionário que diagnosticou o perfil dos sujeitos ecoculturais desta localidade (BORGES SOBRINHO et al., 2020a; 2020b).

O comportamento populacional destes sujeitos de queima se refere a

uma cultura de queima de limpeza praticada por homens e mulheres, de maioria parda, com idade superior a 30 anos, renda mensal de até $\mathrm{R} \$ 1.000,00$, com escolaridade diversificada, residência de 2 a 10 anos no bairro, com observação constante de queimas e queimadas em todo ano, e, dissímil prática presente e/ou passada de queimas. (BORGES SOBRINHO et al., 2020b)

Vale destacar que as queimas de limpeza correspondem aos incêndios florestais Classe I, ou seja, àqueles com área de queima de até $0,10 h a$, contudo, os índices de focos de calor ativo no Tocantins estão referenciados aos incêndios florestais Classe V, àqueles superiores a 200ha, e que correspondem a 89,47\% de seus registros (SOARES et al., 2002; LIMA et al., 2018).

Diante destes dados contraditórios, houve a necessidade de aprofundamento epistemológico aos saberes ecoculturais dos sujeitos residentes no Bairro Lagoa da Ilha, e sob a continuidade da aprovação do Comitê de Ética em Pesquisas Humanas da Fundação Universidade Federal do Tocantins - CEP/UFT, com Parecer Consubstanciado aprovado no 3.853.151 em 21 de fevereiro de 2020, houve realização de Entrevista após aplicação do Questionário (BORGES SOBRINHO et al., 2020b).

O questionário validou 30/43 dos respondentes, contudo, dois optaram por não ceder entrevista, logo havia uma possibilidade de 28 cessões de entrevista, não obstante, seis contatos foram registrados como inexistentes, logo 22 contatos foram possíveis de serem realizados (BORGES SOBRINHO et al., 2020 b). 


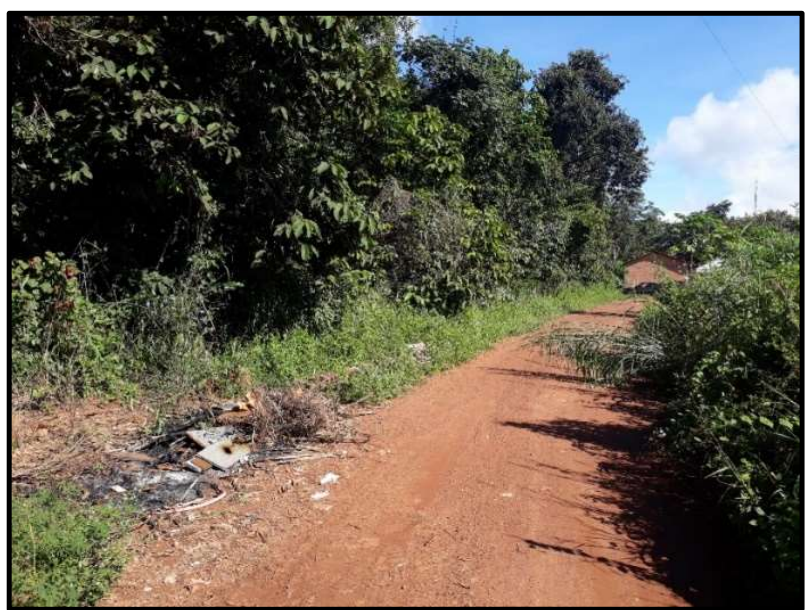

Fotografia 1: Indícios de queima de limpeza na Avenida Contorno, porção sul do Bairro Lagoa da Ilha.

Em 07 de junho de 2020 foi realizado contato telefônico para agendamento presencial à entrevista, contudo, diante da pandemia todos foram unânimes em ceder informações durante a própria ligação. Dos 22 contatos realizados, 11 mantiveram interesse em ceder a entrevista, mas destes, três foram excluídos ao afirmar serem habitantes temporários do Bairro Lagoa da Ilha, então, houve realização oito entrevistas, por meio das quais se delimitou compreensões aos saberes ecoculturais dos residentes do ponto focal urbano de queimas no Tocantins.

Na primeira questão os entrevistados apresentaram três vertentes à compreensão do fogo, na qual $5 / 8$ relacionaram o fogo à destruição, $1 / 8$ apontou a dependência humana ao fogo, e 2/8 apontaram pontos positivos e negativos. Estas respostas apontam para o caráter dicotômico que Bachelard (1994) correlaciona o fogo à humanidade.

A segunda questão personificava a natureza diante de uma queimada, e oportunizava a cada entrevistado a descrição imaginária de tal situação, ao que todos elencaram sentimentos dolorosos e apontaram sensações de destruição, tristeza e doença.

A terceira questão oportunizava ao entrevistado uma oportunidade de contribuição à pesquisa, ao que 6/ afirmaram não ter o que contribuir, 1/8 referenciou que deveria constar a "necessidade de queima para cultivo das lavouras", e, 1/8 solicitou que este estudo fosse encaminhado às autoridades competentes e aos incendiários da agropecuária do município de Lagoa da Confusão.

Por fim, foi oportunizado a manifestação de interesse em participação de um Curso de Formação de Brigadistas Florestais - CFBF, caso o mesmo ocorresse no próprio município, a fim de estabelecer novos conhecimentos e oportunizar uma mudança práticas ecoculturais, ao que 4/8 afirmaram interesse nesta qualificação profissional.

Portanto, houve necessidade de realização de entrevista ao comparar os dados coletados e interpretados pelo questionário com as produções científicas associadas, uma vez que as classes de incêndios florestais não eram correspondentes, e, das 28 possíveis participações houve oito contribuições, sendo que ao final quatro entrevistados mostraram interesse em participar de um CFBF. 


\section{O Curso de Formação de Brigadistas Florestais}

Por meio do Termo de Cooperação no 31/2020 celebrado entre a Prefeitura Municipal da Lagoa da Confusão e Corpo de Bombeiros Militar do Tocantins - CBMTO, na data de 06 de abril de 2020, houve ajustes para que a corporação militar promovesse de forma gratuita o CFBF e a Prefeitura realizassem a contratação de no mínimo 25 brigadistas florestais aprovados no referido curso.

A respectiva capacitação profissional foi subsidiada pela Ordem de Operação no 004/2020/CEPDEC, assinada em 05 de junho de 2020, na qual a Coordenadoria Estadual de Proteção e Defesa Civil - CEPDEC, órgão subordinado ao CBMTO, intermediaria o CFBF por meio de treinamento, entrega de materiais didáticos digitais, relação dos discentes aptos, fornecimento dos certificados digitais com QR-Code aos brigadistas florestais contratados pelo município e a criação de uma Brigada Florestal com foco à prevenção e ao combate às queimadas e incêndios florestais.

O CFBF do município de Lagoa da Confusão foi agendado para os dias 23 e 24 de junho de 2020 e aconteceu na Escola Dona Júlia Pelegrini, com a participação de 39 alunos, sendo 30 pela Prefeitura, seis brigadistas florestais da Fazenda Batira e três participantes da entrevista desta pesquisa.

No primeiro dia do curso os discentes foram orientados à segurança individual e coletiva quanto ao COVID-19, receberam máscaras de tecido e instruções quanto à constante lavagem das mãos com água e sabão e cuidados gerais para evitar a aglomeração. Em seguida foram ministradas instruções teóricas de: primeiros socorros, materiais e equipamentos operacionais, e, prevenção e combate aos incêndios florestais.

No segundo dia da qualificação profissional os discentes realizaram as atividades práticas de reconhecimento da área delimitada para queima, verificação do sentido e força do vento, análise de fatores externos, leitura do incêndio florestal, operações de combate, primeiros socorros em ambientes naturais e manutenção de materiais e equipamentos.

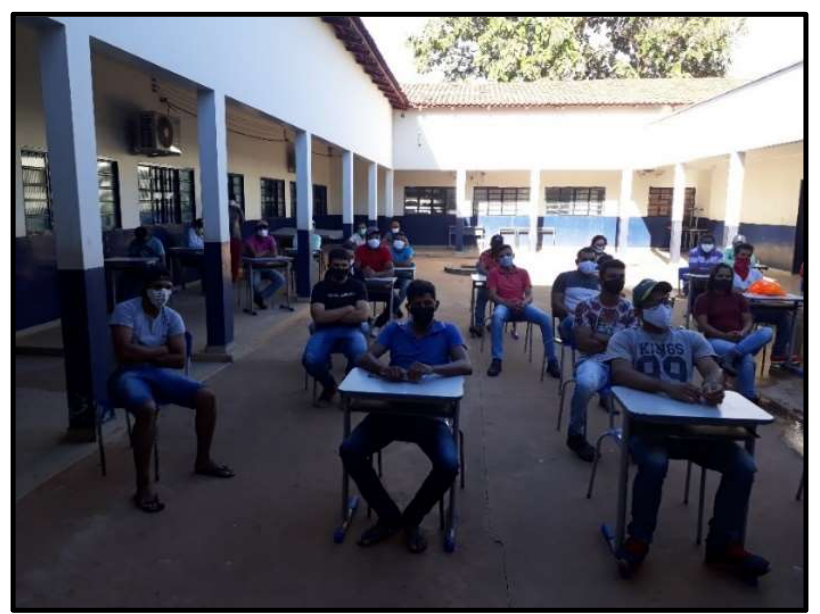

Fotografia 2: Alunos do CFBF durante as instruções teóricas na Escola Dona Júlia Pelegrini.

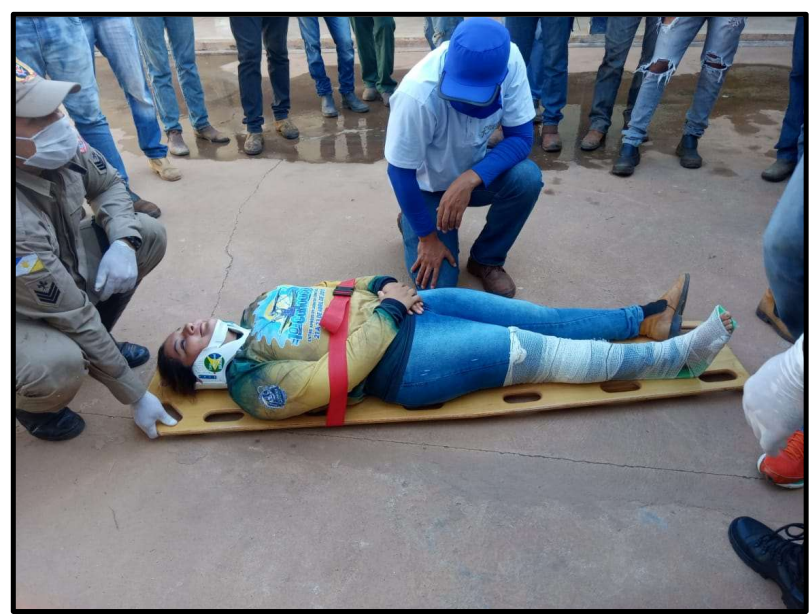

Fotografia 3: Atividade prática de primeiros socorros em ambientes naturais.

Na chegada à área delimitada para queima os discentes são divididos em duas equipes, na qual uma realiza o treinamento prático de combate ao incêndio florestal enquanto a outra equipe observa as ações e ao mesmo tempo permanece a postos para extinção das chamas caso estas saiam da área delimitada. Após 
a primeira atividade prática ocorre o revezamento das equipes.

Após o treinamento de cada equipe chega o momento da avaliação, no qual toda a área delimitada será incendiada e todos os discentes atuarão juntos em um combate que tem por prioridade a segurança, e como missões secundárias realizar a leitura do incêndio florestal e impedir que o fogo saia da área delimitada.

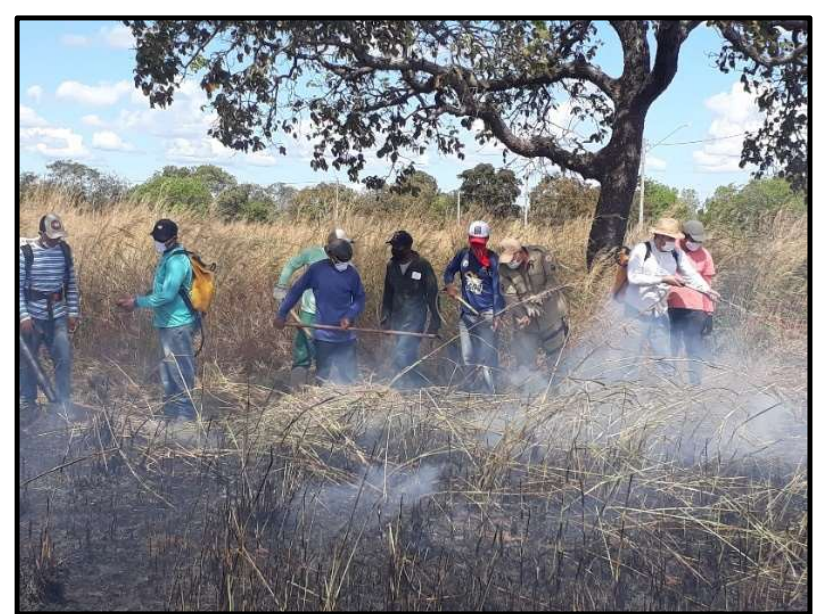

Fotografia 4: Primeira atividade prática em equipe para combate ao incêndio florestal na área delimitada.

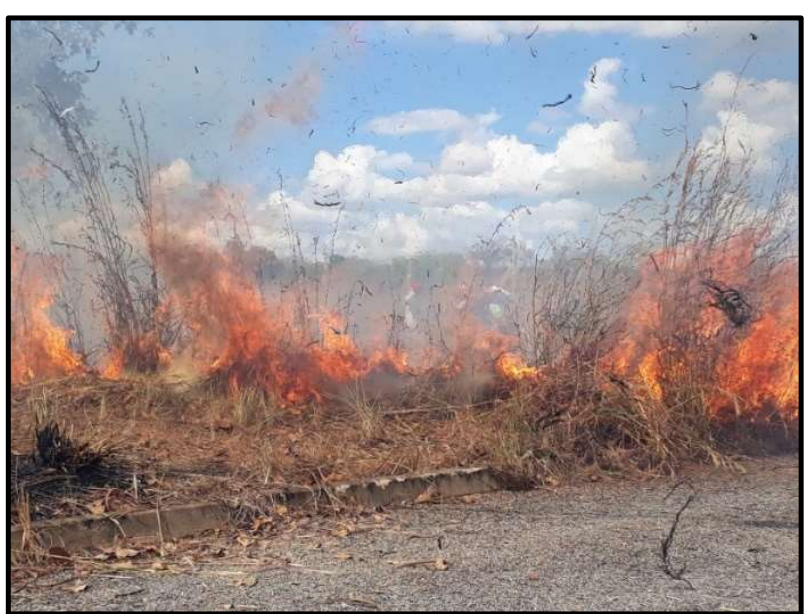

Fotografia 5: Incêndio florestal com incidência de ventos na área de treinamento.

Mesmo com altas chamas e ventos constantes, os alunos mais experientes orientam os neófitos a cercarem a área de queima enquanto eles atuam com o vento pelas costas e fazem uso dos abafadores, das bombas costais e de um soprador, ao que em tempo menor do que o previsto debela todo incêndio com a segurança exigida e ainda protegem uma pequena área interna.

Ao término do combate a área delimitada é vistoriada para fins de extinção de possíveis pontos de reignição, em seguida se realiza um procedimento de segurança para verificar se todos os participantes estão bem e se houve alguma intercorrência, para em seguida operacionalizar a conferência, limpeza e manutenção dos materiais e equipamentos.

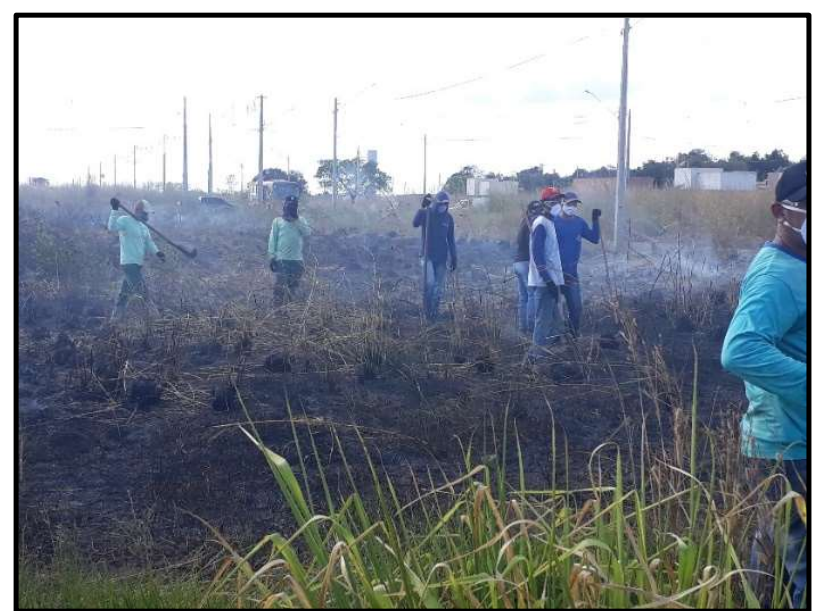

Fotografia 6: Grande incêndio florestal debelado com segurança coletiva.

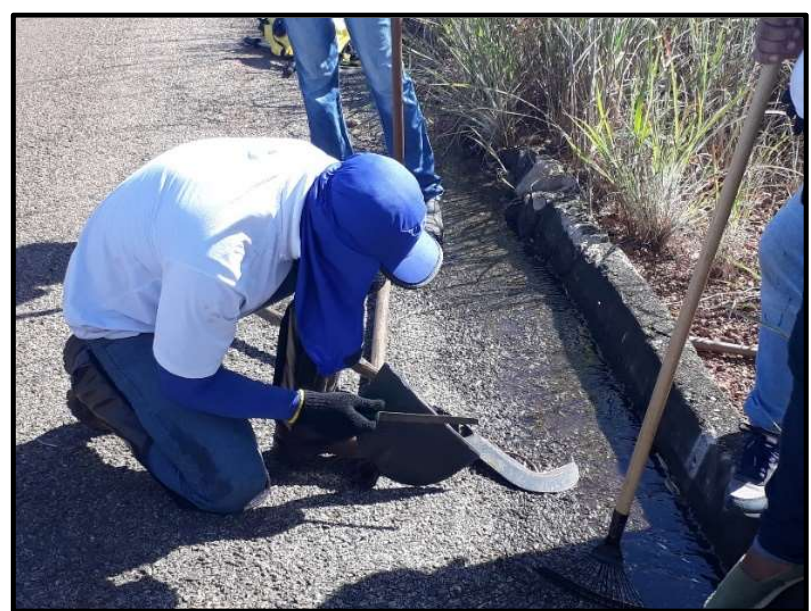

Fotografia 7: Conferência, limpeza e manutenção dos materiais e equipamentos utilizados no combate ao incêndio florestal durante o CFBF.

Após a finalização da capacitação profissional é aplicado um feedback de toda atividade desenvolvida nos dois dias do curso, e oportunizado aos discentes a participação discursiva para destaque dos pontos 
positivos e dos pontos a melhorar, a qual teve por resposta unânime um resultado classificado como positivo.

Ao término do CFBF todos os discentes participantes alcançaram aprovação e não houve registros de lesões a nenhum dos envolvidos, e um relatório de aprovação foi encaminhado à Prefeitura Municipal de Lagoa da Confusão por meio da Coordenadoria Municipal de Proteção e Defesa Civil - COMPDEC.

\section{METODOLOGIA}

Esta pesquisa está subsidiada por produções científicas interdisciplinares que referenciem a discussão qualitativa com a análise quantitativa dos sujeitos ecoculturais do ponto focal urbano dos incêndios florestais do Tocantins por meio da aplicação de uma entrevista autorizada pelo CEP da UFT e da participação em um Curso de Formação de Brigadistas Florestais.

Esta pesquisa se configura como caráter quali-quantitativo por conter investigações científicas multidisciplinares por meio da pesquisa bibliográfica e análise documental; coleta, análise e interpretação dos dados advindos da aplicação de entrevistas aos sujeitos ecoculturais do lócus da pesquisa; e, uma pesquisa de campo real no Curso de Formação de Brigadistas Florestais (CRESWELL, 2010).

Trata-se de uma pesquisa explicativa quanto ao objetivo e à justificativa em virtude da correlação dos saberes ecoculturais com os fenômenos de queima, da aplicação da entrevista aos sujeitos ecoculturais respondentes de um prévio questionário, e, da participação voluntária em um Curso de Formação de Brigadistas Florestais (ANDRADE, 2002; CRESWELL, 2010; BORGES SOBRINHO et al., 2020a).

Em análise às fontes de informação, esta pesquisa subsidia a investigação qualitativa por apresentar os referenciais bibliográficos para fundamentação da discussão teórica e as análises documentais para validação da legalidade do Curso de Formação de Brigadistas Florestais; e ao mesmo tempo a investigação quantitativa é de análise dedutiva sob os aportes estatísticos associadas à entrevista e às variáveis correlacionadas (CRESWELL, 2014; LEMOS et al., 2015; SEVERINO, 2017; SOARES et al., 2017).

Destaca-se que a entrevista é uma continuidade da metodologia investigativa já referenciada por Borges Sobrinho e Ramos Júnior (2020b), quando da aplicação de um Questionário aos sujeitos ecoculturais do ponto focal urbano dos focos de calor do Tocantins, localizado no Bairro Lagoa da Ilha, do município de Lagoa da Confusão.

A realização de entrevista está amparada pelo CEP/UFT sob CAEE no 24786419.0.0000.5519, com financiamento próprio do pesquisador, e Parecer Consubstanciado aprovado no 3.853.151, sem a necessidade de aprovação da Comissão Nacional de Ética em Pesquisa - CONEP, com data de registro em 21 de fevereiro de 2020 .

A entrevista referenciou três questionamentos e ratificou o convite de participação voluntária a um CFBF com objetivo de possibilitar aos sujeitos ecoculturais do ponto focal urbano uma intervenção na realidade do ponto focal urbano das queimas no Tocantins.

Logo, por se tratar de uma pesquisa de campo real, resta ainda apontar um procedimento metodológico que estabeleça a dialética da ação, ou seja, a familiarização dos pesquisadores à população do lócus da pesquisa, cuja base epistemológica entre ambos é o fenômeno em estudo, ao que foi definida a 
pesquisa-ação sob a concepção barbieriana.

Na pesquisa-ação, é criada uma situação de dinâmica social radicalmente diferente daquele da pesquisa tradicional. O processo, o mais simples possível, desenrola-se frequentemente num tempo relativamente curto e os membros do grupo envolvido tornam-se íntimos colaboradores. A pesquisa-ação utiliza os instrumentos tradicionais da pesquisa em Ciências Sociais, mas adota ou inventa novos. (BARBIER, 2007)

A aplicação da pesquisa-ação compreende um processo de etapas o qual se inicia com as delimitações da população e da amostragem correspondentes, a qual iniciou com os quantitativos dos domicílios particulares permanentes ocupado e fechado para aplicação do questionário, com posterior validação para realização de entrevista, que após sua validação, culminou na participação do CFBF (IBGE, 2020; BORGES SOBRINHO et al., 2020b).

A saber, a primeira população (P1) se tratou da soma das espécies habitação de "Domicílio particular permanente ocupado" e "Domicílio particular permanente fechado", e a amostragem correspondente (A1) foi o total de respondentes do questionário aplicado. Os questionários validados desta A1 se tornaram a segunda população (P2) para participação da entrevista por meio de ato voluntário, e o total de interessados em conceder a Entrevista se tonou a segunda amostragem (A2).

Estes interessados em conceder uma entrevista se tornaram a terceira população (P3), e àqueles que efetivaram sua participação compuseram a terceira amostragem (A3), a qual corresponde à quarta população (P4); dentre estes os que haviam respondido no Questionário o interesse em participar de um CFBF se tornaram a quarta amostragem (A4). Dentre os interessados nesta qualificação profissional, os quais se tornaram a quinta população (P5), aqueles que efetivaram sua presença no curso compuseram a quinta e última amostragem (A5). A relação é esquematizada a seguir:

Quadro 1: Esquematização descritiva População-Amostragem da pesquisa.

\begin{tabular}{|l|l|l|}
\hline Ordem & População & Amostragem \\
\hline 01 & P1 $=\sum$ Domicílios particulares permanentes & A1 = Respondentes do P1 \\
\hline 02 & P2 = Questionários validados da A1 & A2 = Interessados em conceder Entrevista do P2 \\
\hline 03 & P3 = A2 & A3 = Entrevistas realizadas \\
\hline 04 & P4 = Entrevistas validadas da A3 & A4 = Interessados em participar de um CFBF \\
\hline 05 & P5 = A4 & A5 = Participantes do CFBF \\
\hline
\end{tabular}

Neste contexto, a pesquisa possui como procedimentos metodológicos um caráter qualiquantitativo, de tipologia explicativa segundo seus objetivos, com pesquisa bibliográfica e análise documental como fontes de informação, seguida de uma pesquisa de campo real com aplicação de questionário para primeira coleta de dados seguida da aplicação de entrevista e posterior participação no CFBF, e, a triangulação entre o pesquisador, o lócus da pesquisa e o fenômeno a ser estudado se deu por meio da Pesquisa-Ação.

\section{RESULTADOS E DISCUSSÃO}

Após estabelecer a População (P1), de 88 domicílios particulares permanentes, alcançou-se uma Amostragem (A1) de 43 respondentes do Questionário, e, após aplicação dos critérios de exclusão foi estabelecida uma População (P2) de 28 validados. 
Dentre as possíveis 28 entrevistas a serem realizadas, houve correspondência da Amostragem (A2) ao total de 22 entrevistas realizadas, as quais se tornaram a População (P3), que ao final desta etapa resultou em uma Amostragem (A3) de 11 entrevistados.

Deste público, após aplicação dos critérios de exclusão, obteve-se a População (P4) com oito entrevistas validadas, das quais quatro apontaram interesse em participar do CFBF, e estes corresponderam às Amostragem (A4) e População (P5). Ao final três participantes compuseram a Amostragem (A5). Os resultados alcançados seguem, em comparativo ao Quadro 01, a esquematização abaixo:

Quadro 2: Esquematização numérica População-Amostragem da pesquisa.

\begin{tabular}{|l|l|l|}
\hline Ordem & População & Amostragem \\
\hline 01 & $\mathrm{P} 1=88$ & $\mathrm{~A} 1=43$ \\
\hline 02 & $\mathrm{P} 2=28$ & $\mathrm{~A} 2=22$ \\
\hline 03 & $\mathrm{P} 3=22$ & $\mathrm{~A} 3=11$ \\
\hline 04 & $\mathrm{P} 4=08$ & $\mathrm{~A} 4=04$ \\
\hline 05 & $\mathrm{P} 5=04$ & $\mathrm{~A} 5=03$ \\
\hline
\end{tabular}

Em análise específica à realização da entrevista, compreende-se por meio da aplicação dos instrumentos que os "professores de queima" são os ascendentes familiares, o que marcou a presença do caráter intergeracional nas práticas de queimas dos sujeitos ecoculturais.

Também se compreendeu que o ato de queimar é uma prática subjetiva, pois 4/8 apontaram o fogo como um agente de limpeza, 3/8 apontaram a queima como um fator destrutivo, e 1/8 afirmou a dicotomia do fogo, como útil para queima de limpeza e destrutivo para a vegetação; logo, a perspectiva bachelardiana se faz presente neste bairro.

Foram ainda apresentadas três Questões aos entrevistados, e por meio da primeira questão o fogo foi compreendido como uma representação de destruição por 5/8, de benefício por 1/8, e dicotômico por 2/8. A segunda Questão, na qual o meio ambiente era personificado diante do fogo, as respostas foram as de maior tempo gasto por todos os entrevistados, e em unanimidade houve a afirmação das sensações de destruição, tristeza e doença.

A última Questão oportunizou a contribuição do entrevistado ao pesquisador, ao que 6/8 afirmaram não ter o que contribuir, $1 / 8$ referenciou a "necessidade" de queima para o cultivo das lavouras, e 1/8 pediu ao pesquisador para mostrasse o resultado desta pesquisa às autoridades competentes e aos incendiários da agropecuária. Vale destacar que 4/8 dos entrevistados apontaram interesse em participar do CFBF, e destes três se fizeram presentes, e ao final todos alcançaram aptidão, tanto na capacitação teórica como nas atividades práticas.

Não obstante, por meio do questionário e da entrevista foi compreendido que os focos de calor do lócus da pesquisa se referem às queimas de limpeza, as quais são caracterizadas como incêndios florestais Classe I, ou seja, aqueles com área queimada em até 0,10ha; ao contraste de que 89,47\% dos incêndios florestais do Tocantins são Classe V (LIMA et al., 2018; BORGES SOBRINHO et al., 2020b).

Diante de tal contradição epistemológica houve necessidade de realizar um comparativo de queimas entre as variáveis de focos de calor com a área queimada, ao que foram selecionados os municípios tocantinenses que na série histórica apresentam área queimada superior a um milhão de hectares, a fim de 
identificar os municípios-chave acometidos pelos incêndios florestais Classe V.

Tabela 1: Municípios tocantinenses em ordem decrescente de área queimada superior a um milhão de hectares ao longo da série histórica 2012-2019.

\begin{tabular}{|c|c|c|c|c|c|c|c|c|c|}
\hline Município & 2012 & 2013 & 2014 & 2015 & 2016 & 2017 & 2018 & 2019 & TOTAL \\
\hline Lagoa da Confusão & $102.400,38$ & $197.847,28$ & $295.997,91$ & $332.958,13$ & $410.000,89$ & $516.239,27$ & $221.338,81$ & $358.215,56$ & $2.434 .998,23$ \\
\hline Formoso do Araguaia & $329.560,34$ & $159.697,74$ & $160.427,84$ & $284.474,70$ & $319.179,42$ & $466.062,92$ & $210.776,89$ & $310.207,46$ & $2.240 .387,31$ \\
\hline Pium & $64.272,74$ & $79.034,45$ & $310.401,46$ & $234.689,39$ & $246.816,17$ & $362.984,43$ & $115.796,09$ & $196.748,78$ & $1.610 .743,51$ \\
\hline Mateiros & $87.410,59$ & $185.920,79$ & $292.569,34$ & $141.450,54$ & $47.088,76$ & $175.631,42$ & $130.730,13$ & $281.372,68$ & $1.342 .174,25$ \\
\hline Goiatins & $189.407,66$ & $101.781,42$ & $189.964,42$ & $81.942,94$ & $146.431,16$ & $289.778,54$ & $100.793,28$ & $195.485,26$ & $1.295 .584,68$ \\
\hline Paranã & $208.937,95$ & $55.262,19$ & $213.535,65$ & $108.025,66$ & $89.531,00$ & $187.747,99$ & $111.889,01$ & $276.859,74$ & $1.251 .789,19$ \\
\hline Ponte Alta do Tocantins & $90.124,98$ & $71.187,91$ & $289.367,06$ & $74.435,67$ & $82.585,19$ & $133.234,53$ & $96.189,64$ & $169.820,56$ & $1.006 .945,54$ \\
\hline
\end{tabular}

Fonte: CEMAF (2020).

Observa-se que a relação é composta por sete municípios e Lagoa da Confusão lidera o ranking, seguido de Formoso do Araguaia e Pium, sendo que estes três municípios estão inseridos na região do centrooeste tocantinense, a qual é conhecida pelo elevado potencial agropecuário. Em contrapartida, correlacionase tais índices com mesmo quantitativo de municípios para a variável de registro de focos de calor ao longo de uma série histórica entre 2009-2018.

Quadro 3: Ordem decrescente dos municípios tocantinenses no ranking dos focos de calor anual na série histórica 20092018.

\begin{tabular}{|l|l|l|l|l|l|l|l|l|l|l|l|l|}
\hline Ord. & Município & $\mathbf{2 0 0 9}$ & $\mathbf{2 0 1 0}$ & $\mathbf{2 0 1 1}$ & $\mathbf{2 0 1 2}$ & $\mathbf{2 0 1 3}$ & $\mathbf{2 0 1 4}$ & $\mathbf{2 0 1 5}$ & $\mathbf{2 0 1 6}$ & $\mathbf{2 0 1 7}$ & $\mathbf{2 0 1 8}$ & Total \\
\hline $\mathbf{1 0}$ & Lagoa da Confusão & 206 & 2206 & 508 & 1747 & 661 & 997 & 1103 & 1893 & 2159 & 662 & 12142 \\
\hline $\mathbf{2 0}$ & Formoso do Araguaia & 202 & 2424 & 740 & 1600 & 480 & 810 & 783 & 1308 & 2101 & 619 & 11067 \\
\hline 39 & Paranã & 279 & 1394 & 448 & 1127 & 260 & 753 & 848 & 494 & 632 & 536 & 6771 \\
\hline 40 & Pium & 111 & 905 & 326 & 739 & 326 & 493 & 656 & 687 & 1390 & 312 & 5945 \\
\hline 5o & Goiatins & 255 & 574 & 583 & 720 & 354 & 601 & 714 & 564 & 990 & 257 & 5612 \\
\hline 60 & Mateiros & 207 & 520 & 441 & 512 & 403 & 470 & 501 & 573 & 798 & 324 & 4749 \\
\hline 70 & Rio Sono & $\mathbf{2 0 0}$ & 741 & 313 & 696 & 297 & 467 & 550 & 505 & 711 & 226 & 4706 \\
\hline
\end{tabular}

Fonte: Tocantins (2019).

Em análise, verifica-se que o município tocantinense de Lagoa da Confusão também lidera o ranking dos focos de calor, logo ele é o ponto focal das queimas, queimadas e incêndios florestais do estado, tanto nas queimas de limpeza, caracterizadas pelos incêndios florestais Classe I, como pelos incêndios florestais Classe V, característicos de limpeza de pasto, desmatamento e preparo do solo para novos plantios (SOARES et al., 2002; LIMA et al., 2018; CLIMAINFO, 2019; BORGES SOBRINHO et al., 2020b).

Diante de todo exposto, compreende-se que os sujeitos ecoculturais do ponto focal de queimas do Tocantins contribuem com os índices de focos de calor no município de Lagoa da Confusão, contudo suas práticas intergeracionais não estão vinculadas à variável de área queimada, uma vez que as classes de incêndios florestais correspondentes são contrapostas entre si.

\section{CONCLUSÕES}

As queimadas são ações antrópicas planejadas que resultam em impactos multidisciplinares, e quando ocorre a perda do controle desta queima se iniciam os incêndios florestais, os quais afetam as relações sociais de geração de renda, segurança alimentar, prestações de serviços de plantio e transporte, e, prejuízos aos consumidores finais das produções.

Os diferentes fenômenos de queima de vegetação são frutos da colonização europeia, e no Brasil ocorrem nos espaços urbanos e rurais, seja para as queimas de limpeza ou para os plantios, todavia, trazem 
como consequências a liberação de fumaça e promovem impactos primários e secundários à biodiversidade.

No Tocantins, as queimas, queimadas e incêndios florestais sofrem influências climatológicas e geomorfológicas naturais, as quais são somadas às práticas antrópicas dos diferentes sujeitos por meio dos saberes ecoculturais correlacionados aos contextos subjetivo e territorial, com destaque às práticas de queima das populações tradicionais.

Tais práticas transfiguram uma nova identidade destes sujeitos e são vinculadas a um contexto econômico para geração de renda e à expansão de novas áreas limítrofes, o que tem por hábito resultar no campesinato imigrante, por meio da saída do espaço rural e da instalação no espaço urbano.

Neste contexto, delimitou-se o ponto focal urbano das queimas no Tocantins, que é o Bairro Lagoa da Ilha do município tocantinense de Lagoa da Confusão, e houve a aplicação dos instrumentos de Questionário e Entrevista em uma pesquisa de campo real para compreender a realidade comportamental dos habitantes deste lócus.

Diante desta metodologia investigativa, compreendeu-se que os saberes ecoculturais dos sujeitos pesquisados são transmitidos de forma intergeracional, e, foi definido como uma estratégia intervencionista a Pesquisa-Ação, por meio da oferta de capacitação profissional no Curso de Formação de Brigadista Florestal.

O CFBF iniciou sob amparo legal das políticas públicas de órgãos estadual e municipal, em obediência aos protocolos de proteção à segurança individual e coletiva quanto ao COVID-19, e teve por conteúdo instruções de primeiros socorros, materiais e equipamentos operacionais, e prevenção e combate aos incêndios florestais.

Ao término desta capacitação profissional todos os discentes foram aptos, alcançaram aprovação e não houve registros de lesões a nenhum dos envolvidos, e um relatório de aprovação foi encaminhado à Prefeitura Municipal de Lagoa da Confusão por meio da Coordenadoria Municipal de Proteção e Defesa Civil.

Diante do exposto, compreendeu-se os saberes ecoculturais dos sujeitos do ponto focal urbano das queimas no Tocantins, o que conclui esta pesquisa como de caráter total, uma vez que todos os objetivos específicos propostos foram alcançados em sua plenitude e, a partir deste momento, este estudo possibilita novos estudos e metodologias para práticas preventivas e ações operacionais no combate aos fenômenos do fogo para minimização os índices associados.

\section{REFERÊNCIAS}

ANDRADE, M. M.. Como preparar trabalhos para cursos de pós-graduação: noções práticas. 5 ed. São Paulo: Atlas, 2002.

AYANZ, J. S. M.; DURRANT HOUSTON, T.; BOCA, R.; LIBERTA G.; BRANCO, A.; RIGO, D.; FERRARI, D.; MAIANTI, P.; VIVANCOS, T. A.; COSTA, H.; LANA, F.; LOFFLER, P.; NUIJTEN, D.; LERAY, T.; AHLGREN, A.. Forest fires in Europe, Middle East and North Africa 2017. EU Publications. 16 ed. Luxembourg: Publications Office of European Union, 2018.

BACHELARD, G.. A psicanálise do fogo. São Paulo: Martins
Fontes, 1994

BARBIER, R.. A pesquisa-ação. Brasília: Líber Livro, 2007.

BICHARA, I. D.. On the river into the woods, in the fields: the playing of the Northeastern Brazilian Indians. In: BICHARA, I. D.; MAGALHÃES, C. M. C.. Children's play and learning in Brazil. New York: Springer, 2018. p.17-27.

BORGES, S. L.; ELOY, L.; SCHMIDT, I. B.; BARRADAS, A. C. S.; SANTOS, I. A.. Manejo do fogo em veredas: novas perspectivas a partir dos sistemas agrícolas tradicionais no Jalapão. Ambiente \& Sociedade, Campinas, v.19, n.3, p.275- 
300, 2016.

BORGES SOBRINHO, C. J.; RAMOS JÚNIOR, D. V.. As queimas e as queimadas no Tocantins: o município de maior registro da série histórica de focos de calor ativos. Revisa IberoAmericana de Ciências Ambientais, Aracaju, v.11, n.01, p.378-390, 2020a. DOI: https://doi.org/10.6008/CBPC21796858.2020 .001 .0034

BORGES SOBRINHO, C. J.; RAMOS JÚNIOR, D. V.. O comportamento populacional e os focos de calor ativo no Setor Lagoa da Ilha. Revisa Ibero-Americana de Ciências Ambientais, Aracaju, v.11, n.06, p.510-521, 2020b. DOI: https://doi.org/10.6008/CBPC2179-6858.2020.006.0041

BORGES SOBRINHO, C. J.; RAMOS JÚNIOR, D. V.. Práticas tranversais contra os incêndios florestais e as queimadas no Tocantins. Revista Flammae, São Luis, v.06, n.15, p.172, 2020c.

CEMAF. Centro de Monitoramento Ambiental e Manejo do Fogo. Incêndios florestais e queimadas no Tocantins. Imagem área queimada X área territorial. Período 2010 a 2019. Palmas: CEMAF/UFT, 2020.

CLEMENTE, S.; OLIVEIRA JÚNIOR, J. F.; LOUZADA, M. A. P.. Focos de calor do bioma Mata Atlântica no estado do Rio de Janeiro: uma abordagem de gestão e legislação ambiental. Revista de Ciências Agroambientais, Alta Floresta, v.15, n.2, p.158-174, 2017.

COELHO, M. C. P.. As narrações da cultura indígena da Amazônia: lendas e histórias. Tese (Doutorado em Linguística Aplicada e Estudos da Linguagem) - Universidade Católica de São Paulo, São Paulo, 2003.

CBMGO. Corpo de Bombeiros Militar do Estado de Goiás. Manual Operacional de Bombeiros: prevenção e combate a incêndios florestais. Goiânia: CBMGO, 2017.

CRESWELL, J. W.. Projeto de Pesquisa: método qualitativo, quantitativo e misto. 3 ed. Porto Alegre: Artmed, 2010.

CRESWELL, J. W.. Investigação qualitativa e projeto de pesquisa: escolhendo entre cinco abordagens. 3 ed. Porto Alegre: Penso, 2014.

DEAN, W.. Joe Foweraker - The Struggle for Land. Hispanic American Historical Review, v.89, n.4, 1984.

DEAN, W.. A ferro e fogo: a história e a devastação da Mata Atlântica brasileira. São Paulo: Cia. das Letras, 1996.

ESCOBAR, A.. O lugar da natureza e a natureza do lugar: globalização ou pós-desenvolvimento. In: A colonialidade do saber: eurocentrismo e ciências sociais-perspectivas latinoamericanas. Buenos Aires: CLACSO, 2005.

GIOVANELLI, L. B.; OLIVEIRA, R. A.; OLIVEIRA FILHO, J. C.; SEDIYAMA, G. C.; CECON, P. R.; BAPTESTINI, J. C. M.. Influência de elementos meteorológicos na evapotranspiração estimada pelo irrigâmetro. Revista Irriga, Boucatu, v.21, n.1, p.58-73, 2016.

HANKINS, D. L.. Ecocultural equality in the Miwko? Waali?. San Francisco Estuary \& Watershed Science, São Francisco, v.16, n.3, 2018.
HAYMAEL, L. B. A.. Diversity in parenting: a qualitative study on the socialization goals of palestinian mothers from different socio-economic backgrounds. Thesis (Doctorate) Illinois State University, Illinois, 2018.

HUONG, D. T.; HUONG, N. T. T.. Ecological culture and educational issue of ecological culture: motivation for the human development. American Journal of Educational Research, Newark, v.6, n.6, p.694-702, 2018.

IBGE. Instituto Brasileiro de Geografia e Estatística. Tocantins. Brasília: IBGE, 2019.

IBGE. Instituto Brasileiro de Geografia e Estatística. Lagoa da Consfusão. Brasília: IBGE, 2020.

LEMOS, F. C. S.; GALINDO, D.; REIS JÚNIOR, L. P.; MOREIRA, M. M.; BORGES, A. G.. Análise documental: algumas pistas de pesquisa em psicologia e história. Psicologia em Estudo, Maringá, v.20, n.3, p.461-469, 2015.

LEPOFSKY, D.; ARMSTRONG, C. G.. Foragig new ground: documenting ancient resource and environmental management in Canadian Archaeology. Canadian Journal of Archaeology, Quebec City, v.42, n.1, p.57-73, 2018.

LIMA, G. S.; FÉLIX, G. A.; TORRES, F. T. P.; COSTA, A. G.; SILVA JÚNIOR, M. R.. Avaliação da eficiência de combate aos incêndios florestais em unidades de conservação brasileiras. Revista Floresta, Curitiba, v.48, n.1, p.113-122, 2018. DOI: http://dx.doi.org/10.5380/rf.v48i1.53550

LYONS, N.; HOFFMANN, T.; MILLER, D.; HUDDLESTAN, S.; LEON, R.; SQUIRES, K.. Katzie \& the Wapato: an archaeological love story. Archaeologies, Springer, v.14, n.1, p.7-29, 2018.

MARIANI, M.; FLETCHER, M. S.. The Southern Annular Mode determines interannual and centennial-scale fire activity in temperate southwest Tasmania, Australia. Geophysical Research Letters, Washington, v.43, p.1702-1709, 2016.

MORELLO, T. F.; RAMOS, R.; STEIL, L.; PARRY, L.; BARLOW, J.; MARKUSSON, N.; FERREIRA, A.. Queimadas e incêndios florestais na Amazônia brasileira: por que as políticas públicas têm efeito limitado? Ambiente $\&$ Sociedade, Campinas, v.20, n.4, p.19-40, 2017. DOI: https://doi.org/10.1590/1809-4422asoc0232r1v2042017

OLIVEIRA, N. M.. Produção agropecuária agregada: uma aplicação para o Estado do Tocantins. Revista Desafios, Palmas, v.5, n.1, 2018.

RAYOL F. O. A.; RAYOL, B. P.. Efeito do fogo na vegetação em sistema agroflorestal, Pará, Brasil. Revista de Ciências Agroveterinárias, Lages, v.19, n.1, 2020.

SAL, A. G.; ALONSO, E. V.; GARCIA, A. G.. Explorando la relación entre saberes y modelos de gestión em las dehesas: la cultura que sustenta el paisaje. In: CONFERÊNCIA IBÉRICA DE ECOLOGIA DA PAISAGEM: A PAISAGEM COMO MODELO E INFRAESTRUTURA PARA A ADAPTAÇÃO DAS SOCIEDADES ÀS ALTERAÇÕES GLOBAIS, 4. Anais. Faro: Universidade do Algarve, 2018. p.106.

SANTOS, P. R.; PEREIRA, G.; CARDOZO, F. S.; RAMOS, R. C.; 
FEIREIRA, A. B. R.; RESENDE, F. C.. Análise das queimadas no cerrado e sua relaão com o NDVI para os anos de 2000 a 2014. Revista de Geografia, Recife, v.35, n.2, p.134-157, 2018. DOI: https://doi.org/10.51359/22386211.2018.229312

SEVERINO, A. J.. Metodologia do trabalho científico. 24 ed. São Paulo: Cortez, 2017.

SOARES, R. V.; SANTOS, J. F.. Perfil dos incêndios florestais no Brasil de 1994 a 1997. Revista Floresta, Curitiba, v.32, n.02, p.219-232, 2002.

SOARES, R. C.; FIGUEIREDO, Â.; GHEDIN, E.. Os processos cognitivos mobilizados pelo ensino com pesquisa na pedagogia universitária. Revista Areté: Revista Amazônica de Ensino de Ciências, Manaus, v.4, n.6, 2017.

SODRÉ, G. R. C.. Fogo e queimadas: histórico, risco e calendário meteorológico na Amazônia Oriental. Tese (Doutorado em Ciências Ambientais) - Universidade Federal do Pará, Belém, 2019.

SOTOMAYOR, J. C.; MILSTEIN, T.. Routledge handbook of ecocultural identidy. New York: Routledge, 2020.

SOTOMAYOR, J. C.; HOFFMANN, J.; OARKS, M. SIEBERT, M.; THOMAS, M.; MILSTEIN, T.. Embodying education: performing environmental meanings, knowledges, and transformations. Journal of Sustainability Education, v.17, p.23, 2018.

SOUZA, A. R. P.. Filhos do encantado: estudo sobre o fenômeno do boto em Novo Airão (AM) a partir do olhar ecossistêmico. Dissertação (Mestrado em Ciências da Comunicação) - Universidade Federal do Amazonas, Manaus, 2018.

TAVARES, S. Q.; BISPO, M. O.. Territórios camponeses no município de Paranã (TO): luta e resistência da comunidade angical. Campo - Território: Revista de Geografia Agrária, Uberlândia, v.15, n.35, p.550-576, 2020.

TOCANTINS. Coordenadoria Estadual de Proteção e Defesa Civil. Série histórica de registros de focos de calor: ranking dos estados brasileiros e municípios tocantinenses. Ofício no 131/2019/CEPDEC e Anexos. SGD 2019/09099/006048. Palmas: CBMTO, 2019.

TURNER, N. J.; DAVIDSON-HUNT, I. J.; O'FLAHERTY, M.. Living on the edge: ecological and cultural edges as sources for diversity for social-ecological resilience. Human Ecology, Springer, n.31, p.439-461, 2003. DOI: http://doi.org/10.1023/A:1025023906459

WHITE, C. A.; PERRAKIS, D. D. B.; KAFKA, V. G.; ENNIS, T. Burning at the edge: integrating biophysical and eco-cultural fire processes in Canada's Parks and protected areas. Fire Eology, Springer Open, v.7, n.1, p.74-106, 2011. DOI: https://doi.org/10.4996/fireecology.0701074

A CBPC - Companhia Brasileira de Produção Científica (CNPJ: 11.221.422/0001-03) detém os direitos materiais desta publicação. Os direitos referem-se à publicação do trabalho em qualquer parte do mundo, incluindo os direitos às renovações, expansões e disseminações da contribuição, bem como outros direitos subsidiários. Todos os trabalhos publicados eletronicamente poderão posteriormente ser publicados em coletâneas impressas sob coordenação da Sustenere Publishing, da Companhia Brasileira de Produção Científica e seus parceiros autorizados. Os (as) autores (as) preservam os direitos autorais, mas não têm permissão para a publicação da contribuição em outro meio, impresso ou digital, em português ou em tradução. 